\title{
UbcD1, a Drosophila ubiquitin-conjugating enzyme required for proper telomere behavior
}

\author{
Giovanni Cenci, ${ }^{1}$ Robert B. Rawson, ${ }^{3}$ Giorgio Belloni, ${ }^{1}$ Diego H. Castrillon, ${ }^{3}$ Mark Tudor, ${ }^{1}$ \\ Romano Petrucci, ${ }^{1}$ Michael L. Goldberg, ${ }^{2}$ Steven A. Wasserman, ${ }^{3}$ and Maurizio Gatti ${ }^{1,4}$ \\ ${ }^{1}$ Dipartimento di Genetica e Biologia Molecolare, Universitá di Roma "La Sapienza," 00185 Rome, Italy; ${ }^{2}$ Section of \\ Genetics and Development, Cornell University, Ithaca, New York 14853-2703 USA; ${ }^{3}$ Department of Biochemistry, \\ University of Texas Southwestern Medical Center, Dallas, Texas 75235-9038 USA
}

The end-to-end association of chromosomes through their telomeres has been observed in normal cells of certain organisms, as well as in senescent and tumor cells. The molecular mechanisms underlying this phenomenon are currently unknown. We show here that five independent mutant alleles in the Drosophila UbcD1 gene cause frequent telomere-telomere attachments during both mitosis and male meiosis that are not seen in wild type. These telomeric associations involve all the telomeres of the $D$. melanogaster chromosome complement, albeit with different frequencies. The pattern of telomeric associations observed in UbcD1 mutants suggests strongly that the interphase chromosomes of wild-type larval brain cells maintain a Rabl orientation within the nucleus, with the telomeres and centromeres segregated to opposite sides of the nucleus. The $U b c D 1$ gene encodes a class I ubiquitin-conjugating (E2) enzyme. This indicates that ubiquitin-mediated proteolysis is normally needed to ensure proper telomere behavior during Drosophila cell division. We therefore suggest that at least one of the targets of UbcD1 ubiquitination is a telomere-associated polypeptide that may help maintain proper chromosomal orientation during interphase.

[Key Words: Drosophila melanogaster; telomere behavior; ubiquitin-conjugating enzymes]

Received October 29, 1996; revised version accepted February 17, 1997.

Telomeres, the DNA-protein complexes at the ends of eukaryotic chromosomes, have long been recognized to have important roles in the protection, replication, and stabilization of chromosome ends (for review, see Harley and Villeponteau 1995; Zakian 1996). Telomeres are also known to influence the expression of adjacent genes, a phenomenon called telomere position effect (for review, see Shore 1995). In most organisms, telomeres are composed of long stretches of conserved, tandemly repeated simple DNA sequences whose addition to chromosome ends is catalyzed by the enzyme telomerase. This is not the case in Drosophila, where telomeres contain multiple copies of the telomere-specific retrotransposons HeT-A and TART instead of simple sequence repeats (for review, see Mason and Biessman 1995; Pardue 1995).

The possibility that telomeres may help organize the architecture of the interphase nucleus is appreciated less widely. Observations of both somatic and meiotic cells suggest that the positioning of telomeres within the nucleus is highly specific and dependent on interactions of telomeres with the nuclear envelope (for review, see Gilson et al. 1993; Dernburg et al. 1995). A nonrandom

\footnotetext{
${ }^{4}$ Corresponding author.

E-MAIL gatti@axcasp.caspur.it; FAX 39-06-44-56-866.
}

distribution of telomeres within the nucleus was first described by Rabl (1885) in amphibia. Rabl noticed that prophase chromosomes have a polarized arrangement, with the telomeres lying at one side of the nucleus and the centromeres clustered at the opposite side. Because this chromosome arrangement was very similar to that seen during the preceding anaphase, he concluded that chromosomes maintain their anaphase configuration throughout interphase. Similar conclusions were reached by Boveri (1909) in his classic studies on Parascaris chromosomes. He also observed that during both telophase and prophase the Parascaris telomeres are accommodated into nuclear evaginations. A Rabl orientation of chromosomes, with telomeres in close proximity to the nuclear envelope, has since been observed during prophase in somatic cells of a variety of organisms. Moreover, there is accumulating evidence that telomeres are associated with the nuclear envelope during interphase (for review, see Dernburg et al. 1995). It is currently unclear whether the relationship between telomeres and the nuclear envelope of somatic cells is a passive consequence of anaphase chromosome orientation or the result of an active process that maintains an ordered nuclear architecture during interphase.

At least during meiosis, dynamic processes appear to be of importance in establishing interactions between 
telomeres and the nuclear envelope. In meiotic cells of several organisms, telomeres are attached to a small region of the nuclear envelope, producing a specialized configuration of chromosomes called the "bouquet arrangement" (Digby 1919). This bouquet structure, which is thought to have a role in chromosome pairing and synapsis, first forms during zygotene by an active process whose molecular basis is not understood (Dernburg et al. 1995).

Abundant evidence indicates that telomeres not only interact with the nuclear envelope but also with each other. In some cases, telomeres are not just found at the periphery of interphase nuclei but are clustered tightly together there. For example, yeast cells immunostained with antibodies against RAP1, a telomere marker, exhibit fewer spots than the expected number of telomeres, suggesting telomere clustering (Klein et al. 1992). In some preparations from plants and certain insects, fibers connecting the telomeres of both homologous and nonhomologous chromosomes have been observed (HughesSchrader 1957; Wagenaar 1969; Stack and Clarke 1973; for review, see Dernburg et al. 1995). The data are particularly convincing in the case of Drosophila polytene chromosomes, where these fibers hybridize in situ with a telomere-specific probe (Rubin 1978). Intriguingly, in rare preparations of somatic nuclei of the coccid Chrysomphalus ficus and of onion and other plant species, all of the chromosomes appear linked together at their ends to form a continuous chain or "spireme" (Hughes-Schrader 1957; Wagenaar 1969).

Normal mammalian cells do not exhibit end-to-end associations of chromosomes. However, such associations have been observed in senescent human fibroblasts (Benn 1976; for review, see Dernburg et al. 1995), in cells from patients with Thiberge-Weissenbach syndrome (Dutrillaux et al. 1978) or ataxia telangiectasia (Hayashi and Schmid 1975; Taylor et al. 1981), and, above all, in a variety of human tumors (for review, see Hastie and Allshire 1989; de Lange 1995). Telomeric fusions in senescent and tumor cells are probably correlated with short telomere length (Counter et al. 1992; Saltman et al. 1993). The frequency of telomeric associations in tumors may therefore be particularly high in early stages of carcinogenesis, before telomerase activation has counteracted replicative telomere shortening (de Lange 1995). It has been speculated that telomeric fusions may have a crucial role in tumor development because the dicentric chromosomes generated by telomeric attachments could result in chromosome breakage and nondisjunction during anaphase, resulting in loss of heterozygosity (Hastie and Allshire 1989; de Lange 1995). Despite the potential involvement of telomeric fusions in carcinogenesis, little is known about the molecular mechanisms underlying this cytological phenomenon.

In this paper we report our investigations on a set of allelic mutations in the Drosophila gene $U b c D 1$ that result in frequent end-to-end associations of chromosomes during both mitosis and male meiosis. The $U b c D 1$ gene encodes UbcD1, a class I ubiquitin-conjugating (E2) enzyme (Treier et al. 1992). Our results suggest that UbcD1 activity is normally required for ubiquitin-dependent proteolysis of proteins that mediate proper telomere behavior during cell divisions in Drosophila.

\section{Results}

\section{The UbcD1 complementation group}

In the course of genetic screens for mutations affecting the fidelity of chromosome segregation in Drosophila, we identified several mutants that exhibited peculiar cytological phenotypes, described in detail below, suggestive of defects in telomere behavior during mitosis and male meiosis. Although these mutations affect different stages of the Drosophila life cycle, the complementation analysis summarized in Figure 1 shows that they are allelic. Because the gene defined by this complementation group encodes a Drosophila ubiquitin-conjugating enzyme (see below), we have called it $U b c D 1$.

As shown in Figure 1, the mutations $U b c D 1^{\text {effete }}$, $U b c D 1^{\text {effetes, }}$, and $U b c D 1^{\text {effetes }}$ (Castrillon et al. 1993; hereafter abbreviated as eff 1 , eff 3 , and eff 8 ) are viable but male sterile and disrupt mitotic but not meiotic telomere behavior. $U b c D 1^{\text {trenino1 }}($ tre 1$)$ is also viable and male sterile, whereas $U b c D 1^{\text {trenino2 }}$ (tre2) is semilethal with sterile male escapers; tre 1 and tre 2 affect both mitotic and meiotic telomeres. Each of these $U b c D 1 \mathrm{mu}-$ tations was associated with the insertion of a marked $P$ element.

We generated new $U b c D 1$ alleles by remobilizing several of the P-element insertions in the locus. One of the resulting mutations, $U b c D 1^{\Delta 73 A}(\Delta 73 A)$, is a deletion that removes almost the entire $U b c D 1$ transcriptional

\begin{abstract}
Figure 1. Complementation analysis among $U b c D 1$ mutant alleles. (ms) Male sterile; $\left(\mathrm{M}^{-}\right)$presence and $\left(\mathrm{M}^{+}\right)$absence of mitotic defects; $\left(\mathrm{m}^{-}\right)$presence and $\left(\mathrm{m}^{+}\right)$absence of meiotic defects; (SL) semilethal; (LL) late lethal; (EL) early lethal. Note that the semilethal and late lethal combinations exhibit both mitotic and meiotic abnormalities.
\end{abstract}

\begin{tabular}{|c|c|c|c|c|c|c|c|}
\hline effl & $\mathrm{ms} \mathrm{M}^{-} \mathrm{m}+$ & & & & & & \\
\hline eff 3 & $\mathrm{~ms} \mathrm{M}^{-} \mathrm{m}+$ & $\mathrm{ms} \mathrm{M}^{-} \mathrm{m}+$ & & & & & \\
\hline eff 8 & $\mathrm{~ms} \mathrm{M}^{-} \mathrm{m}+$ & $\mathrm{ms} \mathrm{M}^{-} \mathrm{m}+$ & $\mathrm{ms} \mathrm{M}^{-} \mathrm{m}+$ & & & & \\
\hline tre 1 & $\mathrm{~ms} \mathrm{M}^{-} \mathrm{m}+$ & $\mathrm{ms} \mathrm{M}^{-} \mathrm{m}+$ & $\mathrm{ms} \mathrm{M}^{-} \mathrm{m}+$ & $\mathrm{ms}^{\mathrm{M}^{-} \mathrm{m}^{-}}$ & & & \\
\hline tre 2 & $\mathrm{~ms}^{\mathrm{M}^{-} \mathrm{m}^{-}}$ & $\mathrm{ms} \mathrm{M}^{-} \mathrm{m}+$ & $\mathrm{ms} \mathrm{M}^{-} \mathrm{m}+$ & $\mathrm{ms}^{\mathrm{M}^{-} \mathrm{m}^{-}}$ & $\mathrm{SL}^{\mathrm{M}^{-} \mathrm{m}^{-}}$ & & \\
\hline$\Delta 112$ & $\mathrm{~ms} \mathrm{M}^{-\mathrm{M}^{-} \mathrm{m}^{-}}$ & $\mathrm{ms} \mathrm{M}^{-} \mathrm{m}+$ & 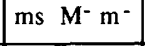 & $\mathrm{ms} \quad \mathrm{M}^{-} \mathrm{m}^{-}$ & $\mathrm{SL} \mathrm{M}^{-} \mathrm{m}^{-}$ & LL $\mathbf{M}^{-} \mathrm{m}^{-}$ & \\
\hline \multirow[t]{2}{*}{$\Delta 73$} & $\mathrm{~ms}^{\mathrm{M}^{-}} \mathrm{m}^{-}$ & $\mathrm{ms}^{\mathrm{M}^{-} \mathrm{m}^{-}}$ & $\mathrm{ms} \mathrm{M}^{-\mathbf{m}^{-}}$ & $\mathrm{ms} \quad \mathrm{M}^{-} \mathrm{m}^{-}$ & LL $\mathbf{M}^{-} \mathrm{m}^{-}$ & LL $\mathbf{M}^{-} \mathrm{m}^{-}$ & $\mathrm{EL}$ \\
\hline & eff 1 & eff 3 & eff 8 & trel & $t r e 2$ & $\Delta 112$ & $\Delta 73$ \\
\hline
\end{tabular}


unit. Another excisant line, $U b c D 1^{\Delta 112}(\Delta 112)$, also disrupts a substantial, though molecularly uncharacterized, portion of the $U b c D 1$ gene. These deletions are lethal in homozygotes and in trans to each other, demonstrating that $U b c D 1$ is an essential gene. For $\Delta 73 A$ homozygotes, death occurs during embryogenesis. The weaker $\Delta 112$ allele causes lethality during the pupal stage, and produces cytological defects in both mitotic and meiotic cells. Both $\Delta 73 A$ and $\Delta 112$, when in trans over eff 1 , eff 3 , or eff 8 , elicit abnormal telomere behavior during male meiosis. Homozygous or heterozygous females for all of the viable $U b c D 1$ mutant alleles are fertile.

\section{Molecular characterization of the UbcD1 gene}

All of the original $U b c D 1$ alleles were obtained from mutagenesis experiments using the mobilization of marked P elements. Several of the mutations have been reverted to wild type by transposase-mediated excision of the P elements, demonstrating that the P-element insertions were the cause of the phenotypes that we have analyzed. To localize the corresponding gene, sequences from within the $\mathrm{P}$ elements were hybridized in situ to polytene chromosomes; all detected a single band of hybridization in polytene chromosome interval $88 \mathrm{D}$ (data not shown).

We were able to clone DNA sequences adjacent to the P-element insertion sites by plasmid rescue (see Materials and Methods). The structure of the genomic region in the vicinity of the $U b c D 1$ P-element mutant insertions is shown in Figure 2. Northern blots indicated that this region gives rise to three related transcripts. One of these transcripts is $2.1 \mathrm{~kb}$ in length and specific to the male germ line. It was observed in RNA from adult wild-type males but not in RNA isolated from either adult wildtype females or the adult agametic progeny of tudor females (Fig. 3A). This germ line-specific transcript was detectable in RNA from pupae and adult males but not earlier stages (data not shown). Two other $U b c D 1$ transcripts, 1.7 and $1.9 \mathrm{~kb}$ in length, are detected in RNA from both male and female wild-type flies, as well as in RNA from agametic flies (Fig. 3B). These RNA species
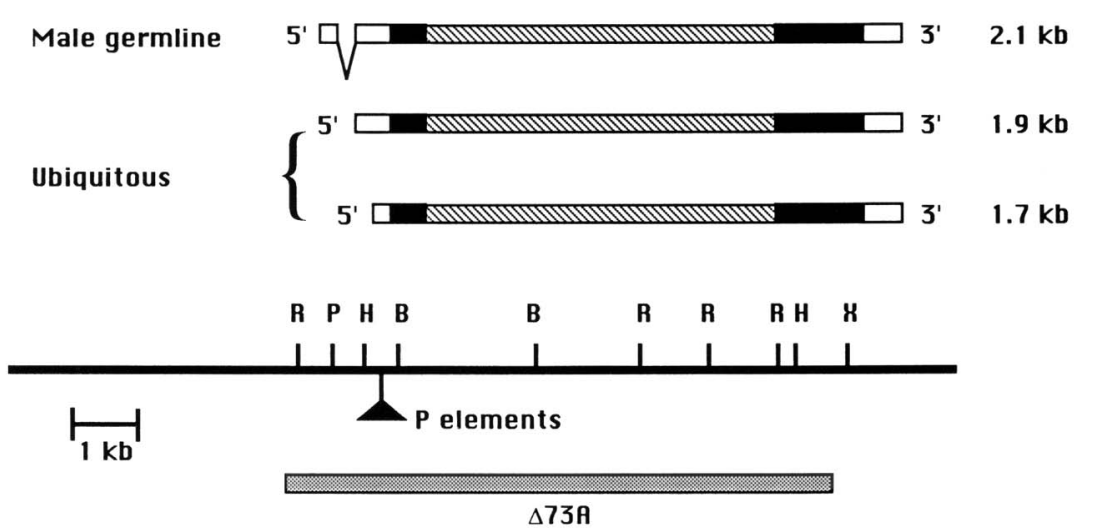

$\longrightarrow 2.1$

AGCGGAAGTTTCAAGAACTCGGAACCAACATCTCAAAATTGCTCAGTAAAAACATTCCG 60

GCAGCCTGCAACACGTTGGGTGTTAACAAATTTACATACAAGGTTGCAAGCTTTTGGGCG 120

CACGCACCATCGATAAGAAGGTAGTCGAATAAAATATAACACCTCCTCGCTGCCGGTAA 180 $\downarrow$

AACTATTTCTTCTGGCTGTTCCCGAACTAAAGCGTTGCCACCCAATCGATCTGGCCACCC 240

CTAGCGAAAAGGTCATATAGCTGGACTGCTCTGCTGGACTTCCGCTTCACAACACTACCA 300 $\begin{array}{lll}\text { e1 } & \text { e3 } & \text { e8 } \\ \nabla & \nabla & \nabla\end{array}$

CACGACACAGACACACCATTCCTCTCGCTCGGGCTTACACTTCGGTGTAACGATTGTGCT 360 $\begin{array}{ccc}\text { e11 } & t 1 & \text { t2 } \\ \nabla & \nabla & \nabla\end{array}$

TCGTTGCGTTCTCAGCTCACTAACGGTCGTCTCTATCGCACAAACGGTCGAAAGGCCCCG 420

D 1.7

CATTGATTGTGAAAAAATAATCGTCGCCGTAGTCTTCGTCGGGTCGCCGTTTTTACTTGC 480

AGTGCGCTGGTGCTGCTTTATTTCGTGACAAGGGACACTCAACCGAAAGAGCCATATTTA 540

AGCATCAAAGTTCTAGAGGCGCAACGCAGCTTTGTGTTTCGTTTTTCGTTCAATTCTAAG 600

CAGGAGGATTATATATTGAATAAAACCCAATCTGTGCGAAGAACAAAAGAAATACGCGA 660

GACACCAACACCAGCACACAACCAACCAAACACACACAACCAACCAAACACACACACAAC 720

CCAGAAAATCAAATTTCAATCAGAAAATGGCGTTAAAAAGAATCAATAAGGAACTGCAAG 780

$\begin{array}{llllllllllll}M & A & I & K & R & I & N & K & E & I & Q & \text { (11) }\end{array}$
Figure 2. Map and partial sequence of the $U b c D 1$ locus. (Top) Map of $U b c D 1$, indicating the location of the transcripts, the P elementinduced mutations used in this study, and the deletion $\Delta 73 A$. The longest, $2.1-\mathrm{kb}$ transcript is specific to the male germ line; two smaller transcripts (1.9 and $1.7 \mathrm{~kb})$ are expressed broadly. Open areas of the transcripts represent exon regions that do not encode part of the $\mathrm{UbcDl}$ protein, solid areas are protein-coding regions of exons. Most of the hatched region of the transcriptional unit is composed of intronic sequences, but the details of intron/exon structure in this region have not been determined. Restriction enzyme recognition sites in genomic DNA: (B) BamHI; (H) HindIII, (P) PstI; (R) EcoRI; (X) XhoI. (Bottom) Partial DNA sequence starting from the $5^{\prime}$ end of the coding strand of a near full-length cDNA representing the male germ-line-specific $(2.1-\mathrm{kb})$ RNA. The downward arrow indicates the position of the 66-bp intron in this transcriptional unit. Rightward-pointing open arrows show the 5 -ends of the longest cDNAs obtained corresponding to the 2.1-, 1.9-, and 1.7-kb transcripts. Inverted triangles represent the sites of P-element insertions associated with $U b c D 1$ mutant alleles. The effete mutations are denoted with $\mathrm{e}$; trenino mutations with $\mathrm{t}$. The complete sequence of this cDNA has been submitted to GenBank under accession no. U68298. 
A
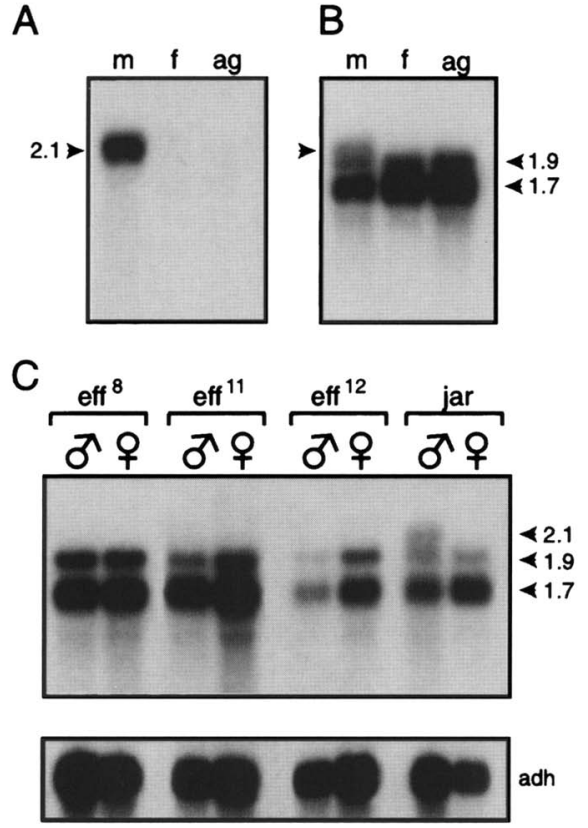

Figure 3. The $U b c D 1$ gene encodes multiple transcripts. Autoradiograph of Northern blots probed with $U b c D 1$ cDNA clones. Sizes are indicated in $\mathrm{kb} .(A, B)$ DNAs were radiolabeled and used as probes against duplicate filter blots of poly $|\mathrm{A}|^{+} \mathrm{RNA}$ (5 $\mathrm{\mu g}$ per lane) from wild-type males $(\mathrm{m})$, wild-type females $(\mathrm{f})$, and from the agametic male and female progeny of tudor females $\langle\mathbf{a g}\rangle$. The filters were probed with a restriction fragment from $(A)$ a male germ-line-specific portion (base pairs 1-173) of the $U b c D 1 \mathrm{cDNA}$ or $(B)$ a restriction fragment from a region of the cDNA (base pairs 731-1226) common to all three transcripts. $(C)$ Filter blot of poly $(A){ }^{+}$RNA (10 $\mu$ g per lane) from flies homozygous wild-type or mutant for the $U b c D 1$ locus, probed as in $B$. The wild-type transcript pattern is seen in adult males and females homozygous for jar, a $\mathrm{P}[\mathrm{Z}]$-induced mutation in an unrelated third chromosome locus required for spermatogenesis (Castrillon et al. 1993). The male germ-line-specific transcript is undetectable in $U b c D 1^{\text {eff }}$ and $U b c D 1^{\text {eff } 12}$ homozygotes. On long exposure, a very low level of this transcript is detectable in $U b c D 1^{e f f i 1}$ males. The probe used for the loading control is a 6-kb EcoRI genomic fragment that spans the entire transcription unit of the D. melanogaster Adh gene.

were found to be expressed throughout development and were especially abundant in early embryos (data not shown). We have obtained near full-length cDNA clones corresponding to each of these three transcripts. Restriction mapping and selected sequence analysis of these cDNAs and the corresponding genomic region has shown that the transcripts are related to each other (Fig. 2). The bulk of the sequences are identical, but the transcripts differ at their $5^{\prime}$ ends. The $2.1-\mathrm{kb}$ male germ-linespecific transcript initiates upstream of the shorter RNAs. The genomic sequence encoding the unique part of this $2.1-\mathrm{kb}$ transcript is interrupted by a 66-bp intron.

By sequencing the DNA flanking the insertions, we found that the original P-element insertions in $U b c D 1$ all mapped to a 200-bp region near the $5^{\prime}$ end of the transcriptional unit. All of the $\mathrm{P}$ elements lie within the second exon of the male germ-line-specific RNA, but all are upstream of the sequences representing the shortest $(1.7 \mathrm{~kb})$ RNA. The tre 1 and tre 2 insertions are within sequences encoding the $5^{\prime}$ end of the 1.9-kb RNA; the positions of some of the remaining $U b c D 1$ mutations with respect to the 1.9-kb RNA are ambiguous, as we do not know the exact $5^{\prime}$ end of this transcript.

Northern blot analysis suggested that the male sterility of $U b c D 1$ alleles was caused by disruption of the male germ-line-specific transcript. The male germ-linespecific transcript was absent or reduced greatly in abundance in adult male RNA from the viable but male-sterile $U b c D 1$ mutant lines (Fig. $3 \mathrm{C}$ ). The constitutive transcripts in these RNA preparations were mostly unaffected, although their abundance appeared to be somewhat lower than in wild type.

All three $U b c D 1$ RNA species give rise to the same protein product. Conceptual translation of the open reading frame (ORF) yielded a polypeptide belonging to the family of highly conserved ubiquitin-conjugating, or E2, enzymes. Database searches revealed that the identical ORF had been identified previously in a PCR screen for Drosophila homologs of yeast E2 genes (Treier et al. 1992). The protein encoded by this Drosophila ORF was designated UbcDl. This protein is very similar in sequence ( $>88 \%$ identity) to the E2 enzymes Ubc- 2 of Caenorhabditis elegans; $\mathrm{UbcH} 5 \mathrm{~A}, \mathrm{UbcH} 5 \mathrm{~B}$, and $\mathrm{UbcH} 5 \mathrm{C}$ of humans; and RnE2/2E and RnE2/4A from rat testis (Zhen et al. 1993; Sheffner et al. 1994; Jensen et al. 1995; Rolfe et al. 1995; Wing and Jain 1995). UbcD1 also exhibits similar but less marked similarity to the Saccharomyces cerevisiae UBC4 and UBC5 proteins $181 \%$ and $82 \%$ identity) and to a family of five to six closely related Arabidopsis thaliana E2 enzymes (Treier et al. 1992; Girod et al. 1993).

\section{Mutations in the UbcD1 gene cause telomeric associations in larval brain cells}

Examination of colchicine-treated brain squashes from larvae bearing various $U b c D 1$ mutant allele combinations revealed a common cytological phenotype. In each case, we observed frequent telomere-telomere attachments that result in a variety of aberrant chromosome configurations (Fig. 4; Table 1). Two main types of telomeric associations can be distinguished: double telomere associations (DTAs) conjoining one pair of sister chromatids with another pair, and single telomere associations (STAs) in which each of the two sister chromatids behaves independently.

In the DTA class, the tips of two sister chromatids can fuse with two other telomeres of either the same chromosome or of a different chromosome. In the former case, this results in a monocentric ring chromosome (Fig. $4 \mathrm{e}, \mathrm{f})$; in the latter case, a dicentric linear chromosome is produced (Fig. $4 \mathrm{~b}, \mathrm{c}, \mathrm{e}, \mathrm{g}, \mathrm{h}, \mathrm{i}$ ). If more than one DTA occurs in a cell, polycentric rings and linear chromosomes carrying three or more centromeres are generated (Fig. $4 \mathrm{~d}, \mathrm{f}, \mathrm{i})$. In a few cases, we observed polycentric chromosomes involving most of the Drosophila genetic comple- 


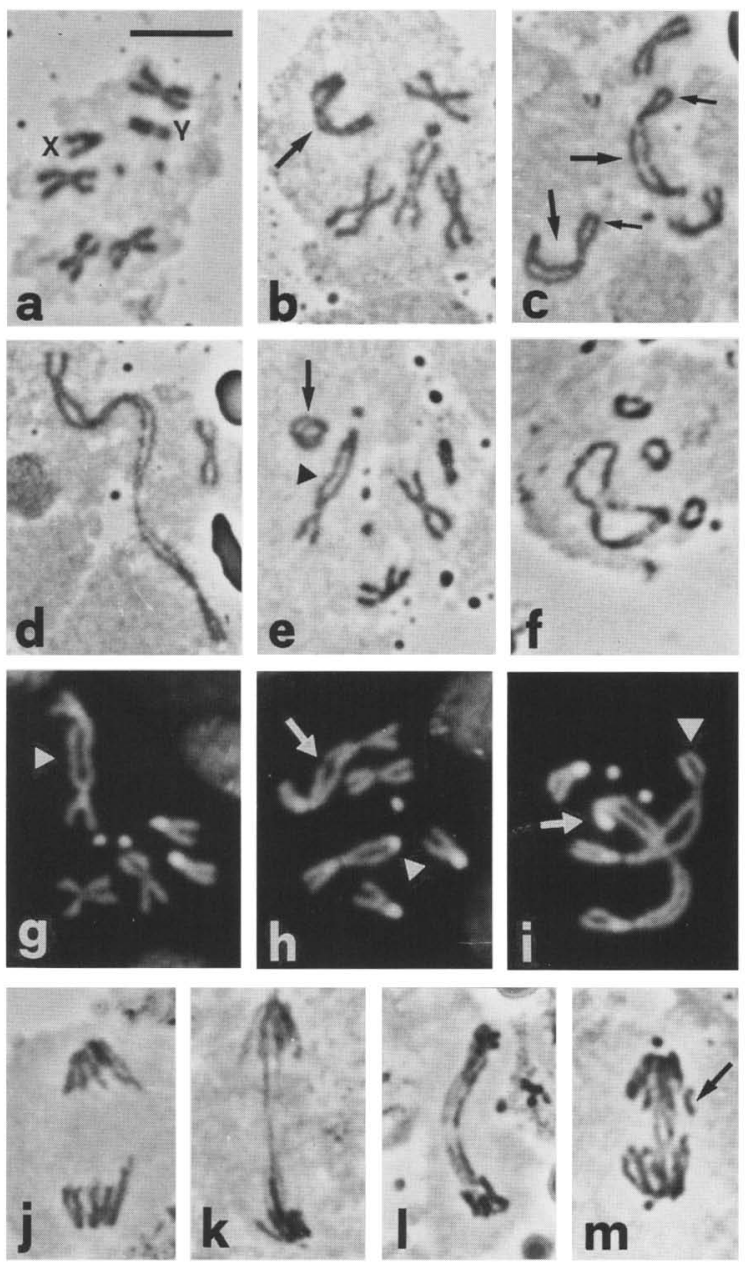

Figure 4. Telomeric associations in larval brain cells of $U b c D 1$ mutants. $(a-i)$ Colchicine-arrested metaphases; $(j-m)$ anaphases from noncolchicine-treated preparations. $(a-f, j-m)$ Aceto-orcein staining; $(g-i)$ Hoechst 33258 staining. (a) Normal male metaphase; $(b)$ a male metaphase with an XL-YS DTA dicentric (large arrow); $|c|$ a female metaphase with two XL-autosome DTA dicentrics (arrows) and two attachments between autosomal sister telomeres (small arrows); $(d)$ a female metaphase showing a trenino (little train) of chromosomes; only one chromosome of the complement is not attached to the trenino; $(e)$ a male metaphase with an XL-autosome DTA dicentric (arrowhead) and a DTA ring autosome (arrow); $(f)$ a female metaphase in which the entire complement is arranged in monocentric or multicentric DTA ring configurations; $(g)$ a female metaphase with a 3-3 DTA dicentric (arrowhead); $(h)$ a female metaphase showing an STA involving chromosomes 2 and 3 (arrow) and a 3-4 dicentric DTA (arrowhead); (i) an XL-2-3 DTA tricentric (arrow) and a 2-3 DTA dicentric (arrowhead); $(j)$ a normal anaphase; $(k)$ an anaphase with a single bridge; (1) an anaphase with two resolved bridges; $(\mathrm{m})$ an anaphase with bridges and an acentric fragment (arrow). Bar, $5 \mu \mathrm{m}$.

ment (Fig. 4d). Two UbcD1 alleles have been named trenino1 and trenino2 after this phenotype, in that the multicentrics resemble a little train (trenino in Italian) of chromosomes.
STAs were overall less frequent than DTAs $(10 \%$ of cells exhibit STAs vs. $18 \%$ for DTAs). The most common type of STAs were those between sister chromatids (Fig. 4c). STAs between nonsister chromatids, resulting in dicentric and polycentric linear configurations, were also observed frequently (Fig. 4h). However, we never observed STAs producing monocentric ring chromosomes. The absence of these rings contrasts with the relatively high frequency of DTA rings and might reflect cell cycle-dependent variations in the distance between the opposite telomeres of the same chromosome (see Discussion).

Aceto-orcein squashes of colchicine-treated brains (Fig. 4a-f) additionally permit an evaluation of the relative frequencies with which the different telomeres are associated. The arms of the telocentric $\mathrm{X}$ and the submetacentric $\mathrm{Y}$ chromosomes are easily identifiable, whereas the large autosomes (chromosomes 2 and 3 ) are seen clearly as metacentrics. However, there are some limitations to this type of analysis. Chromosomes 2 and 3 cannot be distinguished from each other; the tiny fourth chromosomes are often difficult to visualize because of their small size. In addition, to minimize errors in scoring, we have restricted our analysis to DTAs, which are the most straightforward configurations. As shown in Table 2 , our data indicate that all of the telomeres can participate in telomere-telomere associations, albeit with different frequencies. The telomeres of the major autosomes and of the left (long) arm of the X chromosome (XL) appear to have similar probabilities of involvement. These telomeres participate in DTAs more often than the XR, YL, YS, and fourth chromosome telomeres.

To ascertain whether the second and third chromosome telomeres were both involved in DTAs, we examined a limited sample of Hoechst-stained $\Delta 112 /$ $\Delta 112$ metaphases (Fig. $4 \mathrm{~g}-\mathrm{i}$ ). Hoechst staining permits unambiguous recognition of each chromosome of the Drosophila melanogaster complement (Gatti et al. 1994). We examined DTAs involving 104 individual telomeres of the large autosomes. Of these, 57 were third chromosome telomeres and 47 second chromosome telomeres. The telomeres of the major autosomes therefore have similar probability of participating in telomeric associations.

To determine the consequences of telomeric associations on subsequent steps in mitosis, we analyzed mitotic figures in non-colchicine-treated mutant brain squashes. This type of preparation allows the examination of both metaphase and anaphase figures. Metaphases showed frequent telomere-telomere attachments, indicating that colchicine has no effect on telomeric interactions in $U b c D 1$ mutants. Many anaphases exhibited single or multiple chromatin bridges that connected the two sets of chromosomes migrating to the opposite poles (Fig. 4k-m; Table 3). However, three lines of evidence suggested that most telomere-telomere attachments that generate these bridges were resolved during anaphase. First, very few of these anaphases displayed lagging acentric fragments (Fig. $4 \mathrm{~m}$; Table 3). Sec- 
Cenci et al.

Table 1. Chromosome abnormalities in colchicine-arrested metaphases from UbcDl mutant larval brains

\begin{tabular}{|c|c|c|c|c|c|c|c|c|c|c|c|}
\hline \multirow[b]{3}{*}{ Genotype } & \multirow{3}{*}{$\begin{array}{l}\text { No. of cells } \\
\text { scored }\end{array}$} & & & \multicolumn{6}{|c|}{ DTAs } & \multirow{3}{*}{$\begin{array}{l}\text { Polyploid/ } \\
\text { hyperploid }\end{array}$} & \multirow[b]{3}{*}{ Breaks $^{\mathrm{e}}$} \\
\hline & & \multicolumn{2}{|c|}{ STAs } & \multicolumn{3}{|c|}{ linear attachments ${ }^{c}$} & \multicolumn{3}{|c|}{ rings $^{d}$} & & \\
\hline & & $\mathrm{su}^{\mathrm{a}}$ & $\mathrm{dic}^{\mathrm{b}}$ & 2 & 3 & $>3$ & 1 & 2 & $>2$ & & \\
\hline tre1/tre1 & 669 & 9 & 22 & 32 & 4 & 1 & 1 & 3 & 2 & 8 & 2 \\
\hline tre $1 / \Delta 112$ & 623 & 45 & 48 & 34 & 2 & 0 & 2 & 0 & 0 & 15 & 1 \\
\hline tre2/tre2 & 419 & 22 & 20 & 62 & 13 & 3 & 13 & 1 & 0 & 1 & 1 \\
\hline tre2/ $\Delta 73$ & 1719 & 77 & 70 & 242 & 34 & 13 & 64 & 10 & 1 & 13 & 11 \\
\hline$\Delta 112 / \Delta 112$ & 841 & 73 & 37 & 160 & 23 & 12 & 22 & 7 & 4 & 21 & 19 \\
\hline Control $^{\mathrm{f}}$ & 481 & 3 & 1 & 1 & 0 & 0 & 0 & 0 & 0 & 2 & 0 \\
\hline
\end{tabular}

${ }^{a}$ Sister unions (i.e., sister telomere attachments).

${ }^{\mathrm{b}}$ This class includes dicentric and polycentric STAs.

${ }^{\mathrm{c}}$ The number of chromosomes involved in linear multicentric figures is indicated below.

${ }^{\mathrm{d}}$ The number of chromosomes involved in ring configurations is indicated below.

'Incomplete chromosome breaks (see text for explanation). Complete chromosome breaks are rare and in the range of controls.

${ }^{\mathrm{f}}$ The Oregon-R wild-type strain was used as a control.

ond, the frequency of metaphases with incomplete chromosome breaks (i.e., metaphases with a broken chromosome without the corresponding acentric fragment, or metaphases with a normal chromosome complement plus an extra acentric fragment) was relatively low (Table 1). These would be produced if anaphase bridges in the previous cell generation remained unresolved, therefore resulting in chromosome breakage, as occurs in 1(1)nod ${ }^{D T S}$ and lodestar mutant neuroblasts (Girdham and Glover 1991; M. Gatti and B.S. Baker, unpubl.). Third, the frequency of hyperploid and polyploid cells was also low (Table 1). A failure in the resolution of telomeric attachments would be expected to impair mitotic chromosome segregation, leading to the formation of hyperploid or polyploid daughter nuclei.

\section{UbcD1 mutations disrupt male meiosis}

Telomere-telomere attachments appear to take place during both meiotic divisions in Drosophila males mutant for $U b c D 1$. In meiotic metaphase II figures we found many STAs $(-20 \%$ in tre 1$)$ but we did not detect DTAs. Observations of metaphase I figures were less conclusive-no telomeric associations between chromosomes of different bivalents were found, whereas the

Table 2. Involvement of individual telomeres in DTAs

\begin{tabular}{lccccccc}
\hline & $\begin{array}{l}\text { No. of } \\
\text { telo- } \\
\text { Sex }\end{array}$ & \multicolumn{5}{c}{ Percent involvement in DTAs } \\
\cline { 2 - 8 } meres $^{\mathrm{a}}$ & $2+3$ & $\mathrm{XL}$ & $\mathrm{XR}$ & $\mathrm{YL}$ & YS & 4 \\
\hline $\mathrm{F}$ & 1298 & 77.2 & 14.8 & 6.4 & - & - & 1.6 \\
& & $(50.0)$ & $(12.5)$ & $(12.5)$ & - & - & $(25.0)$ \\
$\mathrm{M}$ & 559 & 77.0 & 5.9 & 3.4 & 4.6 & 4.3 & 4.5 \\
& & $(50.0)$ & $(6.25)$ & $(6.25)$ & $(6.25)$ & $(6.25)$ & $(25.0)$ \\
\hline
\end{tabular}

The analysis was performed on the DTAs observed in the various mutant combination reported in Table 1. The expected frequencies are in parentheses.

aTotal number of telomeres involved in DTAs. tight pairing of the homologs did not permit a reliable scoring of DTAs and STAs within the bivalents. However, clear evidence that telomeric associations must occur in meiosis I as well as meiosis II was obtained from the analysis of meiotic anaphases and telophases. In $U b c D 1$ mutants, $60 \%-80 \%$ of ana-telophase I and $40 \%-$ $60 \%$ of anaphase II figures exhibited lagging chromatin between the two sets of migrating chromosomes (Fig. 5; Table 4). This type of meiotic abnormality was never seen in wild type. Mutant anaphases and telophases had completely normal spindles, indicating that the observed meiotic defects were not attributable to problems in spindle structure (Fig. 5).

To determine the nature of the lagging chromatin, we examined methanol/acetic acid-fixed anaphases stained with aceto-orcein. In tre $1 /$ tre 1 mutants, $81 \%$ of anaphase I and $39 \%$ of anaphase II figures displayed apparently acentric chromosome fragments between the daughter nuclei (Fig. 6A, c and d; Table 5). A much lower proportion of these anaphases $(4 \%$ of anaphase I and $13 \%$ of anaphase II cells) exhibited either intact lagging chromosomes (Fig. 6A,e) or nondisjunction (Fig. 6A,f).

To confirm that most of the lagging chromosomal ma-

Table 3. Effects of UbcDl mutants on neuroblast anaphases

\begin{tabular}{|c|c|c|c|c|c|c|}
\hline \multirow[b]{2}{*}{ Genotype } & \multirow{2}{*}{$\begin{array}{l}\text { No. of } \\
\text { anaphases } \\
\text { scored }\end{array}$} & \multirow[b]{2}{*}{ Normal } & \multicolumn{3}{|c|}{$\begin{array}{l}\text { Irregular } \\
\text { anaphases }^{\text {a }}\end{array}$} & \multirow{2}{*}{$\begin{array}{l}\text { Percent } \\
\text { aberrant } \\
\text { anaphases }\end{array}$} \\
\hline & & & A & B & $\mathrm{C}$ & \\
\hline tre1/tre1 & 90 & 57 & 8 & 22 & 3 & 36.6 \\
\hline tre $1 / \Delta 112$ & 66 & 40 & 3 & 18 & 5 & 39.4 \\
\hline tre2/tre2 & 153 & 100 & 17 & 34 & 2 & 34.6 \\
\hline 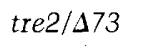 & 223 & 137 & 21 & 55 & 10 & 35.9 \\
\hline$\Delta 112 / \Delta 112$ & 83 & 44 & 20 & 19 & 0 & 47.0 \\
\hline Control $^{\mathrm{b}}$ & 200 & 200 & 0 & 0 & 0 & 0 \\
\hline
\end{tabular}

${ }^{\mathrm{a}}$ (A) One chromatid bridge; (B) two or more chromatid bridges; (C) lagging acentric fragments between poles.

bregon-R. 

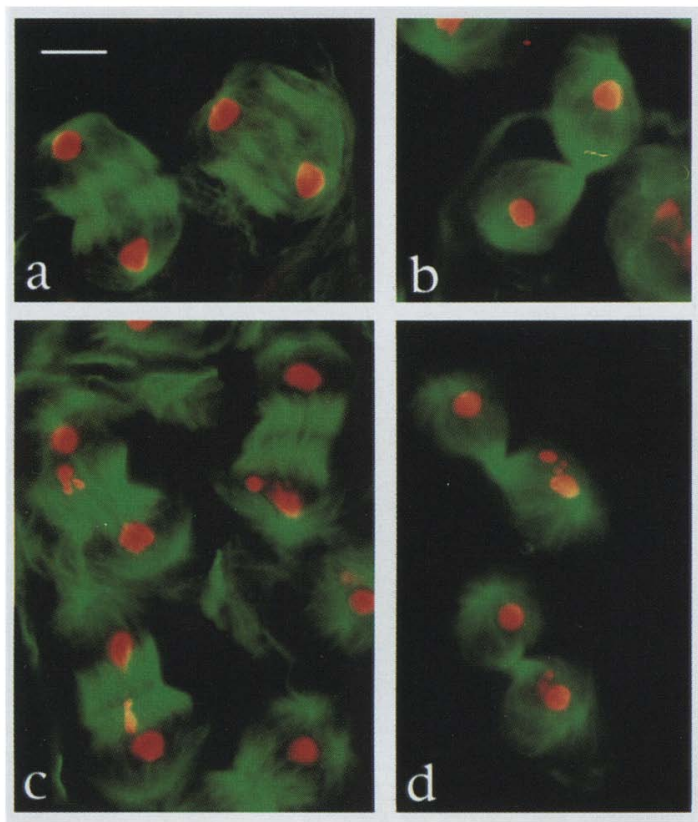

Figure 5. Lagging chromatin in meiotic anaphases and telophases I of UbcD1 mutant males. Shown are wild-type anaphases $(a)$ and telophases $(b)$ and anaphases $(c)$ and telophases $(d)$ from $U b c D 1$ mutant testes. To visualize tubulin and DNA, testes were sequentially stained with antitubulin antibodies (green) and Hoechst 33258 (red). Note that the UbcD1 mutants have normal spindles with prominent central zones but exhibit lagging masses of chromatin. Bar, $10 \mu \mathrm{m}$.

terial consisted of acentric fragments, we performed fluorescent in situ hybridization (FISH) using probes specific for the pericentric regions of either the $\mathrm{X}$ or the third chromosome (see Materials and Methods). The results of these experiments showed that in the large majority of cases, the centromeric regions of the $\mathrm{X}$ and third chromosomes had properly migrated toward the poles, indicating that the lagging chromatin was composed mainly of acentric fragments (Fig. 6B; Table 5).

In summary, the high frequency of metaphase II STAs, as well as the abnormalities seen in meiotic anaphases and telophases, strongly suggest that telomere-telomere attachments occur frequently in $U b c D 1$ meiotic meta-

Table 4. Meiotic abnormalities in UbcDl mutants

\begin{tabular}{|c|c|c|c|c|}
\hline \multirow[b]{2}{*}{ Genotype } & \multicolumn{2}{|c|}{ Anaphase $\mathrm{I}^{\mathrm{a}}$} & \multicolumn{2}{|c|}{ Anaphase $I^{\mathrm{a}}$} \\
\hline & Total & $\operatorname{lag}(\%)$ & Total & $\operatorname{lag}(\%)$ \\
\hline tre1/tre1 & 94 & 73 & 184 & 51 \\
\hline tre2/tre2 & 67 & 70 & 45 & 40 \\
\hline 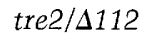 & 87 & 62 & 48 & 40 \\
\hline$\Delta 112 / \Delta 112$ & 55 & 81 & 38 & 62 \\
\hline Control $^{\mathrm{b}}$ & 50 & 0 & 50 & 0 \\
\hline
\end{tabular}

Meiotic anaphases and telophases were stained with anti-tubulin antibodies and Hoechst 33258 (see Fig. 5).

a (lag) anaphases and telophases that exhibit a lagging chromatin. ${ }^{\mathrm{b}}$ Oregon-R. phases. In contrast to brain cells, these attachments are not resolved, causing chromosome breakage during anaphase.

\section{Mutations in UbcD1 do not affect female meiosis}

Females homozygous or heterozygous for all the $U b c D 1$ viable, male-sterile alleles are fertile. Therefore, we examined female meiosis by mating mutant females with males carrying a marked attached XY chromosome, allowing us to screen the progeny for phenotypes indicating XX and nullo-X nondisjunctional events in their mothers (see Materials and Methods). Of a total of 2113 progeny from tre $1 /$ tre 1 females, we found no exceptions. In addition, no exceptions were found in 948 progeny from tre2/tre2 females and 1084 progeny from tre2/ $\Delta 112$ females. We conclude that $U b c D 1$ mutations do not affect female meiosis substantially.

\section{Discussion}

The role of $\mathrm{UbcDl}$ in the ubiquitin-mediated pathway

Selective protein degradation by the ubiquitin-proteasome pathway has a crucial role in many cellular regulatory mechanisms, including those that govern the cell cycle (for review, see Jentsch 1992; Deshaies 1995; Hoschstrasser 1995). Ubiquitin-mediated proteolysis is a multistep process. Ubiquitin is first linked by a thiol ester bond to a ubiquitin-activating, or E1, enzyme. Activated ubiquitin is then transferred to a ubiquitin-conjugating, or E2, enzyme. Finally, this enzyme, often in cooperation with the accessory factor ubiquitin ligase, or E3, donates ubiquitin to a substrate protein. Repeated ubiquitination cycles lead to multiubiquitinated proteins that are degraded rapidly by the $26 \mathrm{~S}$ proteasome. Most cells have several E2 enzymes and an unknown number of E3 factors, leading to the suggestion that the E2 and E3 factors may interact combinatorially to determine substrate specificity (Jentsch 1992; Chen et al. 1993; Hochstrasser 1995).

The $U b c D 1$ gene encodes a class I E2 enzyme (Jentsch 1992; Treier et al. 1992). Class I E2 proteins, such as the $\mathrm{UbcDl}$ protein, contain only the $16-\mathrm{kD}$ UBC domain common to E2 proteins (Jentsch 1992). Class I E2 enzymes function poorly in vitro in the absence of an E3 factor (Hershko and Ciechanover 1992). Other E2 enzymes contain additional sequences at either the carboxyl terminus (class II) or amino terminus (class III) and often carry out efficient ubiquitin conjugation without the addition of E3s (Jentsch 1992).

The UbcDl protein exhibits a strong homology with the $S$. cerevisiae E2 enzymes UBC4 and UBC5, which perform overlapping functions along with UBC1. Deletion of the gene for one of these enzymes results in no evident phenotype; deletion of two of the three renders yeast sensitive to a variety of stresses; deletion of all three is lethal (Seufert and Jentsch 1990; Treier et al. 1992). The Drosophila UbcD1-coding sequence has been transformed into yeast under the control of the yeast 
A
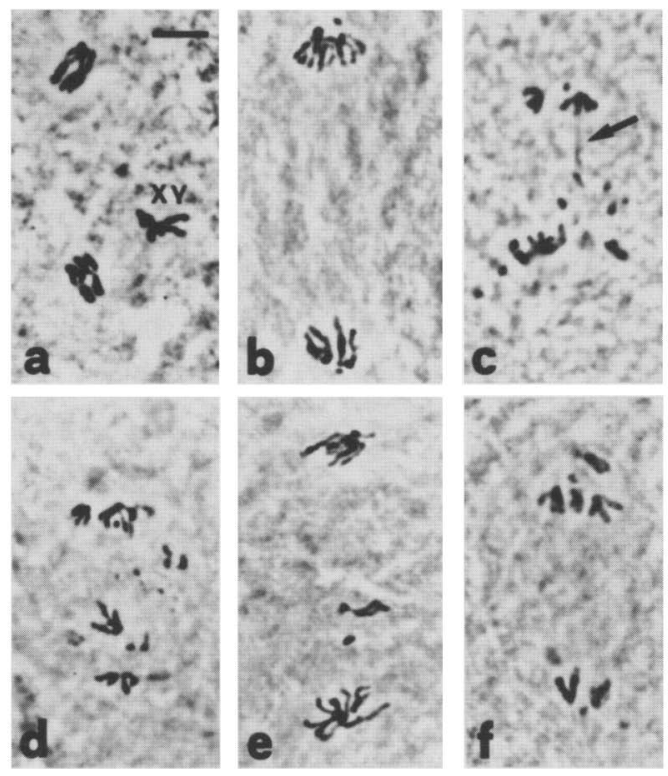

B
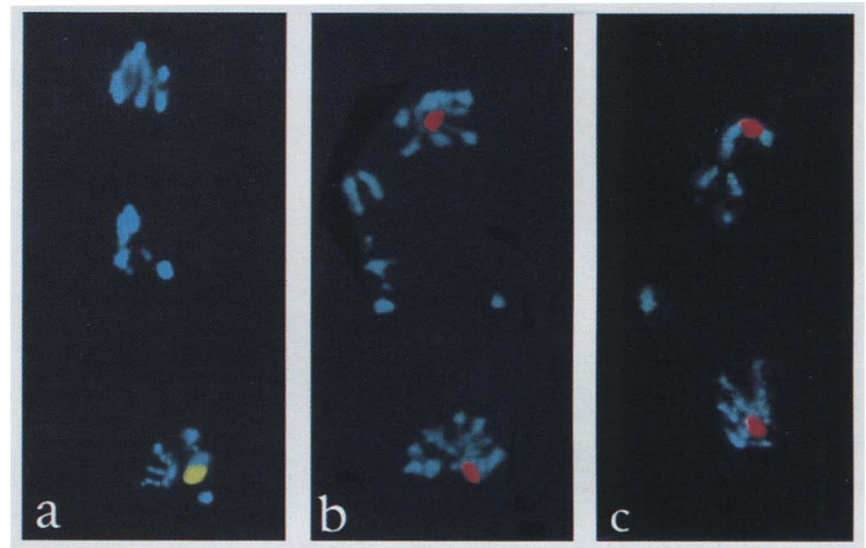

Figure 6. Abnormal meiotic chromosome segregation in $U b c D 1$ mutant males. $|A|$ Orcein-stained wild-type $\{a, b\rangle$ and $U b c D 1$ mutant testes $(c-f)$. (a) A meiotic metaphase I in wild type; the chromosome ends are often closely associated because of the tight pairing of the homologs. This makes it very difficult to assess directly the presence of telomeric associations in UbcD1 mutants (see text for further explanation). (b) A normal anaphase $I_{;}(c)$ a mutant anaphase I showing a broken chromatin bridge (arrow) and acentric fragments; $(d)$ a mutant anaphase I with multiple lagging acentric fragments; $(e)$ a mutant anaphase I with two apparently intact lagging chromosomes (X and fourth); $(f)$ a mutant anaphase I in which a pair of homologs has failed to disjoin properly. Bar, $5 \mu \mathrm{m}$. $(B)$ In situ hybridization with the 359-bp satellite repeats ( $a$, yellow signal) and the dodecasatellite DNA ( $b, c$, red signals), which mark specifically the pericentric heterochromatin of the X and the third chromosome, respectively. $(a, b) U b c D 1$ mutant meiotic anaphase I figures; $(c)$ a $U b c D 1$ mutant meiotic anaphase II. Note that in each case there is no hybridization on the lagging chromatin between the poles.

$U B C 4$ promoter. This construct rescues a number of defects of yeast UBC4 UBC5 double mutants, restoring ubiquitin-mediated proteolysis of abnormal polypeptides (Treier et al. 1992). It is therefore quite likely that $U b c D 1$ mediates ubiquitin-dependent proteolysis in flies.

Little is known about the substrates of class I E2 enzymes. UBC4 and UBC5 act synergistically with two other E2 enzymes to target the yeast MAT $\alpha 2$ protein for degradation (Chen et al. 1993). Either the human $\mathrm{UbcH} 5 \mathrm{~B}$ and $\mathrm{UbcH} 5 \mathrm{C}$ enzymes, or the related $A$. thaliana E2 enzyme AtUBC8, can in the presence of E6E6AP complex (which acts as an E3 factor), mediate p53 ubiquitination (Sheffner et al. 1994; Rolfe et al. 1995).

Our cytological observations of phenotypes associated with five independent $U b c D 1$ mutant alleles

Table 5. Meiotic chromosome segregation in trel/trel males

\begin{tabular}{lccccc}
\hline $\begin{array}{l}\text { Experiment, } \\
\begin{array}{l}\text { meiotic } \\
\text { division }\end{array}\end{array}$ & $\begin{array}{l}\text { No. of } \\
\text { anaphases } \\
\text { scored }\end{array}$ & Regular & $\begin{array}{l}\text { Lagging } \\
\text { acentric } \\
\text { fragments }\end{array}$ & $\begin{array}{l}\text { Lagging } \\
\text { chromosomes }\end{array}$ & Nondisjunction \\
\hline A,I & 91 & 13 & 74 & 2 & 2 \\
A,II & 78 & 38 & 30 & 6 & 4 \\
B,I & 61 & 9 & 52 & 0 & 0 \\
B,II & 57 & 36 & 20 & 0 & 1 \\
C,I & 54 & 23 & 30 & 1 & 1 \\
C,II & 41 & 19 & 22 & 1 & \\
\hline
\end{tabular}

a) The analysis was performed by scoring aceto-orcein-stained meiotic squashes. (B and C) The anaphase figures were examined after FISH with either the 359-bp satellite DNA probe (B) that labels the pericentric heterochromatin of the X chromosome or with the dodecasatellite probe $(C)$ that marks the pericentric heterochromatin of the third chromosome. In both $\mathrm{B}$ and $\mathrm{C}$ the anaphases with lagging acentric fragments and those with lagging chromosomes exhibit unlabeled and labeled lagging chromatin, respectively. In $\mathrm{A}$ the nondisjunction class includes any nondisjunctional events, whereas in B and C it solely refers to labeled chromosomes. 
show clearly that $\mathrm{UbcD} 1$ is required for proper telomere behavior. However, at least in the male germ line, $\mathrm{UbcD} 1$ is likely to have additional functions. The leaky mutants eff 1 , eff 3 , and eff 8 do not exhibit abnormal telomere behavior during male meiosis, but are nonetheless sterile. This suggests that UbcD1 is also needed for ubiquitination of proteins required in postmeiotic stages of spermatogenesis.

\section{The origin and fate of telomeric associations}

Larval brain metaphases exhibit two types of telomeretelomere associations, DTAs and STAs. Neither kind of chromosomal configuration results from chromosome or chromatid exchanges because they are never accompanied by acentric fragments. Nevertheless, dicentric and ring DTAs are structurally similar to mutagen-induced chromosome exchanges generated during $G_{1}$, whereas STAs have the same appearance as chromatid exchanges produced during S- $\mathrm{G}_{2}$ (Savage 1970). This suggests that DTAs arise from telomere-telomere fusions that occurred during $\mathrm{G}_{1}$ and that are replicated and maintained subsequently in $\mathrm{S}-\mathrm{G}_{2}$. STAs are likely to be the consequence of associations between telomeres of chromosomes that have replicated already.

The formation of both DTAs and STAs requires the physical proximity of telomeres during interphase. Telomeres would be clustered at one side of the nucleus if chromosomes maintained their anaphase configuration in the subsequent interphase, as suggested by Rabl (1885). In D. melanogaster, a Rabl orientation of chromosomes is evident in both polytene salivary gland nuclei (Mathog et al. 1984; Hochstrasser and Sedat 1987) and embryonic nuclei (Foe and Alberts 1985; Hiraoka et al. 1990; Dernburg et al. 1996), though not in polytene chromosomes from the larval midgut (Hochstrasser and Sedat 1987), in imaginal discs, and neuroblast nuclei (Dernburg et al. 1996). To explain these findings, Dernburg et al. (1996) suggested that during the short embryonic interphases, chromosomes do not have sufficient time to relax from their anaphase configuration and, therefore, maintain a Rabl orientation throughout interphase. However, in later stages of development, when interphase is much longer, the chromosomes would have the time to assume a more compact arrangement within the nucleus.

Our observations on $U b c D 1$ mutants suggest that the chromosomes of actively dividing brain cells maintain a residual Rabl conformation during early interphase (i.e., the $G_{1}$ phase), but progressively lose it as these cells proceed through the cycle. That chromosomes continue to be arranged in a Rabl configuration for at least part of the interphase is suggested by the finding that, in both males and females, $\mathrm{XL}$ is involved in DTAs with a higher frequency than XR. Because XL is nearly the same length as the arms of the large metacentric autosomes, whereas $\mathrm{XR}$ is extremely short, in a Rabl configuration one would expect the tip of XL to be closer to the telomeres of the major autosomes than would be the tip of XR (Fig. 7). Moreover, two findings suggest that chromosomes relax

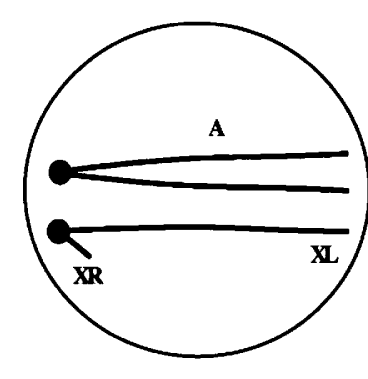

\section{G1}

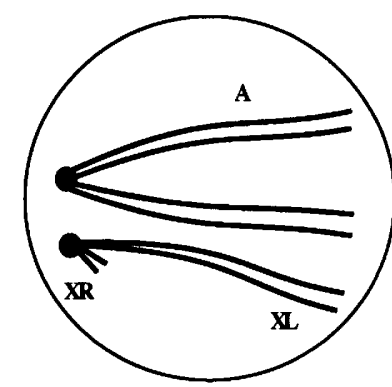

S-G2
Figure 7. A model for chromosome organization in interphase nuclei of Drosophila larval brain cells. Only a large metacentric autosome $(A)$ and the subtelocentric $\mathrm{X}$ chromosome are represented $_{i}$ the centromeres are depicted as solid circles. We propose that during $G_{1}$ the chromosomes maintain the same arrangement as in the preceding telophase, with the opposite autosomal telomeres in close physical proximity and the tip of XL closer to these telomeres than the tip of XR. During the $S-G_{2}$ phases the chromosomes relax from the Rabl configuration, so that the opposite autosomal telomeres are no longer as close to each other as during $G_{1}$.

from the Rabl orientation as brain cells proceed through the cycle. The observation that DTAs are more frequent than STAs can be interpreted as indicating that chromosome ends disperse when cells pass from $G_{1}$ to $S-G_{2}$. Similarly, the higher frequency of DTA rings compared with the STA rings may reflect cell-cycle-dependent variations in the Rabl conformation. During $G_{1}$ the opposite telomeres of the same chromosome would be sufficiently close to interact to form DTA rings. However, the proximity of opposite telomeres would be reduced later in the cell cycle, preventing STA ring formation (Fig. 7).

Although our results show that telomeric associations must occur during both meiotic divisions, we believe these are restricted only to certain kinds of interactions. We did not detect interactions between telomeres of chromosomes in different bivalents during meiosis I, nor did we observe DTAs in meiotic metaphases II. The absence of telomeric associations between chromosomes in different meiotic bivalents is anticipated, because as early as prophase I, the bivalents are physically separated, which would prevent interactions between heterologous chromosomes (Cooper 1965; Cenci et al. 1994). The failure of mutant metaphase II figures to show the presence of DTAs may reflect the fact that after the first meiotic division, secondary spermatocytes do not go through an S phase and are therefore unlikely to generate DTAs (see above).

Although most telomere-telomere associations in larval brain cells are resolved during anaphase, telomeric associations in male meiotic chromosomes fail to be resolved and give rise to chromosome breakage during anaphase. One explanation for this difference is that telomeres of meiotic chromosomes are connected more tightly than those of mitotic chromosomes. Alterna- 
tively, these cells may differ in the mechanics or speed of anaphase chromosome movement and therefore the application of forces across telomere associations during anaphase $\mathrm{A}$. This is conceivable because the meiotic spindle is much larger than the mitotic spindle /Cenci et al. 1994) and the maximum distance between the separating sets of anaphase chromosomes is higher in meiosis than in mitosis $(10 \mu \mathrm{m}$ in mitosis vs. 30 and $18 \mu \mathrm{m}$ in the first and second meiotic division, respectively). Additional support for the latter hypothesis is the finding that although $\sim 60 \%$ of mutant meiotic anaphases exhibit lagging acentric fragments, only $2 \%$ of these cells display chromatin bridges. This suggests that meiotic anaphase bridges persist for a shorter time than those found in somatic cells, implying that meiotic anaphase $\mathrm{A}$ is more rapid than mitotic anaphase in brain cells.

Interestingly, we found no evidence of chromosome loss and nondisjunction during meiosis of $U b c D 1 \mathrm{mu}-$ tant females. One interpretation of these results is that telomere-telomere associations do occur in female meiosis but they are resolved before or during anaphase, as is the case for mitosis. Alternatively, female meiotic chromosomes might not undergo end-to-end associations. Ultrastructural studies on chromosome organization in Drosophila female pachytene nuclei support this second alternative. In these cells the pericentric regions of the chromosomes lie at one side of the nucleus but the telomeres are neither clustered in the typical bouquet arrangement nor obviously associated with the nuclear envelope (Carpenter 1975).

\section{The basis for telomeric associations in UbcD1 mutants}

Although our findings demonstrate that UbcD1 is required for proper telomere behavior, they do not prove that this enzyme interacts directly with telomeric proteins. For example, one could argue that telomeric associations might be the consequence of changes in cellcycle timing, which cause chromosome end tangling. This is clearly not the case. The cytological phenotype of $U b c D 1$ mutants is unique, in that none of the many Drosophila mitotic mutants, including those that cause more or less severe delays in the cell cycle, exhibit telomeric associations (i.e., see Gatti and Baker 1989). In addition, although telomeric associations have been observed in senescent and cancer cells, to the best of our knowledge, no one has reported that they can be induced by impairing proper progression of the mammalian cell cycle. Finally, and perhaps most importantly, Moazed and Johnson (1996) have found recently that the SIR4 protein of yeast telomeres binds the deubiquitinating enzyme UBP3, suggesting that telomeric protein ubiquitination is a general phenomenon.

Therefore, we propose that the telomeric associations we have observed in $U b c D 1$ mutant mitoses and male meioses result from failure to degrade one or more telomere-associated proteins. We do not know the identity of these putative polypeptide targets of UbcD1. Telomeres in Drosophila are unique in their absence of short repeats and appear to be maintained by transpositions of particular retrotransposons to the chromosome ends (Mason and Biessman 1995; Pardue 1995). Unfortunately, little is currently known about proteins that bind to these HeT-A and TART retrotransposons, or to components of subtelomeric heterochromatin.

There are three ways in which proteins could mediate telomere-telomere associations (Gilson et al. 1993). The most straightforward is that dimers or other multimers of a telomere-binding protein might be able to associate simultaneously with two telomeres. This model has been proposed to explain protease-sensitive telomeric associations in ciliate macronuclei (Lipps et al. 1982). Another possibility is that proteins may link telomeres indirectly, through a third element such as a component of the nuclear envelope. Finally, it is conceivable that telomere-associated proteins might facilitate DNA-DNA interactions between telomeres. The $\beta$ subunit of the Oxytrichia telomere protein and the RAPl protein of yeast have the ability to help fold or stabilize simple repeat telomeric DNA into G-quartet structures that mediate telomere-telomere associations in vitro (Fang and Cech 1993; Giraldo and Rhodes 1994; for review, see Henderson 1995). Although $G$ quartets are unlikely to exist in Drosophila telomeres, protein-stabilized DNA-DNA interactions between either retrotransposons or other components of subtelomeric heterochromatin might explain the nucleic acid-containing fibers that link telomeres in polytene chromosomes (Rubin 1978).

Observations in many different kinds of cells indicate that the clustering and association of telomeres is a widespread aspect of nuclear architecture (see introductory section). We therefore believe that the most straightforward explanation of our results is that during at least some part of interphase in wild-type Drosophila cells, telomeres are normally associated directly or indirectly through UbcDl targets. Action of the UbcD1 enzyme disrupts this association by prophase, where telomere-telomere interactions are not observed normally. Therefore, the metaphase and anaphase telomeric associations observed in $U b c D 1$ mutants would be the consequence of the failure to degrade these protein targets of the ubiquitin pathway.

\section{Materials and methods}

\section{Genetic strains}

The $U b c D 1^{\text {tre } 1}$ and $U b c D 1^{\text {tre2 }}$ mutant alleles were isolated by a cytological screen of a collection of male sterile mutants generated in the laboratory at the Universitá di Roma "La Sapienza," Italy. These mutants were obtained by transposition of the P[1acW] element (Bier et al. 1989), according to the mutagenesis scheme described by Gatti and Goldberg (1991).

The mutations $U b c D 1^{\text {eff } 1}, U b c D 1^{\text {eff } 3}$, and $U b c D 1^{\text {eff } 8}$ have been described previously as alleles of effete /Castrillon et al. 1993); these have been renamed as alleles of the $U b c D 1$ gene on the basis of the studies reported here. $U b c D 1^{\text {eff } 1}$ and $U b c D 1^{\text {eff } 3}$ represent insertions of a $\mathrm{P}\left[\right.$ neo $\left.^{r}\right]$ element (Berg and Spradling 1991); UbcD $1^{\text {eff } 8}$ is caused by insertion of the $\mathrm{P}\left[1 a c Z, \mathrm{ry}^{+}\right]$element (Mlodzik and Hiromi 1992). All the $U b c D 1$ mutant alleles were balanced over TM6c, which carries the dominant markers $S b$ and $T b$. This allows unambiguous recognition of homozy- 
gous mutant larvae and pupae based on their non- $T b$ phenotype. The $t u d^{1}$ mutation used to generate agametic flies has been described previously (Boswell and Mahowald 1985). Marker mutations and balancer chromosomes are cataloged in Lindsley and Zimm (1992).

To analyze X chromosome segregation in $U b c D 1$ mutant females, we crossed these flies with males carrying an attached $\mathrm{XY}$ marked with $y$ and $B^{s}$, as well as a normal Y chromosome. The progeny from these crosses were then scored for exceptional non- $B^{s}$ females and y $B^{s}$ males.

\section{P-element excision}

Mobilization of P-element insertions in $U b c D 1^{\text {eff }}$ alleles was carried out as described by Eberhart and Wasserman (1995). Many excisants of $U b c D 1^{\text {eff } 8}$ and of other $U b c D 1^{\text {eff }}$ alleles were precise excisions that reverted the mutant phenotype to wild type (data not shown). Several imprecise excisions of $U b c D 1^{\text {eff } 8}$ were obtained, including the deletions $U b c D 1^{\Delta 73 A}$ and $U b c D 1^{\Delta 112}$ described in the text. Similar procedures used to mobilize the $\mathrm{P}[1 a c W]$ element in the $U b c D 1^{\text {tre } 1}$ and $U b c D 1^{\text {tre }}$ alleles are described by Gatti and Goldberg (1991); again, many precise excisants that exhibited wild-type phenotypes as homozygotes were obtained.

\section{Nucleic acid manipulations}

Preparation of fly genomic DNA, agarose gel electrophoresis, library screening, Southern blotting, Northern blotting, hybridization, autoradiography, DNA sequencing, and sequence analysis were as described previously (Eberhart and Wasserman 1995). All genomic clones were isolated from a $\lambda$-EMBL3 $D$. melanogaster genomic library provided by J. Tamkun (University of California, Davis). cDNA clones for the male germ-linespecific $U b c D 1$ transcript were isolated from a testis cDNA library (the gift of T. Hazelrigg, Columbia University, New York, NY) and from an adult male cDNA library (from T. Karr, University of Illinois, Urbana), both prepared in the $\lambda$-Zap phagemid vector (Stratagene). Plasmid clones of positive inserts were obtained by the in vivo phagemid rescue technique according to the manufacturer's protocol. cDNA clones for embryonic $U b c D 1$ transcripts were obtained from a 0 - to 3-hr embryonic cDNA plasmid library (Brown and Kafatos 1988).

\section{Isolation of genomic DNA flanking $P$ insertions}

Ten fly-equivalents of genomic DNA from $U b c D 1^{\text {effete }}$ insertion-bearing strains were digested with $N$ heI and $X b a I$, SpeI and $X b a \mathrm{I}$, or $X b a \mathrm{I}$ alone. Similar amounts of genomic DNA from the $U b c D 1^{\text {trenino }}$ mutations were cut with either EcoRI or PstI. The digested genomic DNA was then ligated $10-14 \mathrm{hr}$ at $18^{\circ} \mathrm{C}$ at high dilution (five fly-equivalents $/ \mathrm{ml}$ ); these conditions favor the circularization of fragments over their concatamerization. The products were collected by ethanol precipitation, redissolved in $10 \mu \mathrm{l}$ of TE buffer, and one-tenth of the resuspended DNA was then used to transform high-efficiency XL-1 Blue cells (Stratagene).

\section{Cytological procedures}

Colchicine-treated metaphase chromosome preparations stained with either aceto-orcein or Hoechst 33258, and acetoorcein stained anaphase figures from larval brains were obtained and analyzed as described by Gatti and Goldberg (1991) and Gatti et al. (1994). Meiotic chromosome preparations were obtained from noncolchicine-treated larval or pupal testes. Testes were dissected in saline buffer $\{0.7 \% \mathrm{NaCl}\}$, transferred to a drop of aceto-orcein (Gatti and Goldberg 1991), and squashed gently.

Meiotic anaphases and telophases simultaneously stained with Hoechst 33258 and anti-tubulin antibodies were prepared as described by Cenci et al. (1994). Tubulin and Hoechst 33258 fluorescence were recorded separately as gray-scale digital images using a cooled charge-coupled device (CCD; Photometrics) and the IP Lab Spectrum software. Images were then converted to Photoshop (Adobe) format, pseudocolored, and merged (for details, see Williams et al. 1995).

\section{In situ hybridization}

The probes used for in situ hybridization were the 359-bp satellite repeats, and the dodecasatellite DNA, which are localized specifically in the pericentric heterochromatin of the $\mathrm{X}$ and the third chromosome, respectively (Lohe et al. 1993; Carmena et al. 1993). The 359 probe was amplified by PCR from whole genomic DNA (parameters from A. Dernburg, Stanford University, Palo Alto, CA), whereas the dodecasatellite probe was synthesized as a 36-bp single-stranded oligomer. Both probes were labeled by primer extension incorporating biotin 11-dUTP. The slides were prepared by squashing gently in $45 \%$ acetic acid larval and pupal testes dissected in saline buffer $(0.7 \% \mathrm{NaCl})$. These slides were then frozen in liquid nitrogen; after removal of the coverslip they were air dried, denatured in $0.2 \mathrm{M} \mathrm{HCl}$ for $30 \mathrm{~min}$ at $37^{\circ} \mathrm{C}$, and then dehydrated in ethanol at room temperature (Lohe et al. 1993). Hybridization conditions, probe detection, and Hoechst 33258 staining are described by Williams et al. (1996).

\section{Acknowledgments}

We thank Dennis McKearin and Chris Shelton for supplying materials; Steve DiNardo, Pierre Gönczy, and Byron Williams for helpful discussions; and Abby Dernburg for kindly providing FISH protocols before publication. We especially thank Angie Duke, Teresa Gallardo, Par Towb, and ZeXiao Li for help in the isolation and analysis of UbcD1 clones. G.C. and M.T. were supported by grants from the Istituto Pasteur, Fondazione Cenci-Bolognetti, and the European Community Human Capital and Mobility Program, respectively. R.R., D.C., and S.A.W. were supported by a grant from the Robert A. Welch Foundation and by the Texas Advanced Research Program under grant no. 003660. M.L.G. received support from the National Institutes of Health (NIH; grant GM48430), and M.G. was supported by grants from the Associazione Italiana per la Ricerca sul Cancro (AIRC), Progetto Finalizzato del Consiglio Nazionale delle Ricerche (CNR) "Ingegneria Genetica," and Progetto Strategico CNR "Ciclo Cellulare e Apoptosi."

The publication costs of this article were defrayed in part by payment of page charges. This article must therefore be hereby marked "advertisement" in accordance with 18 USC section 1734 solely to indicate this fact.

\section{References}

Benn, P.A. 1976. Specific chromosome aberrations in senescent fibroblast cell lines derived from human embryos. Am. I. Hum. Genet. 28: 465-473.

Berg, C.A. and A.C. Spradling. 1991. Studies on the rate and site-specificity of $\mathrm{P}$ element transposition. Genetics 127: 515-524.

Bier, E., H. Vaessin, S. Shepherd, K. Lee, K. McCall, S. Barbel, L. Ackerman, R. Carretto, T. Uemura, E. Grell, L.Y. Jan, and Y.N. Jan. 1989. Searching for pattern and mutation in the Drosophila genome with a P-lacZ vector. Genes \& Dev. 
3: $1273-1287$

Boswell, R.E. and A.P. Mahowald. 1985. tudor, a gene required for assembly of the germ plasm in Drosophila melanogaster. Cell 433: 97-104.

Boveri, T. 1909. Die blastomerenkerne von Ascaris megalocephala und die Theorie der Cromosomen-indiviualität. Arch. Zellforsch. 3: 181-268.

Brown, N.H. and F.C. Kafatos. 1988. Functional cDNA libraries from Drosophila embryos. J. Mol. Biol. 203: 425-437.

Carmena, M., J.P. Abad, A. Villasante, and C. Gonzales. 1993. The Drosophila melanogaster dodecasatellite sequence is closely linked to the centromere and can form connections between sister chromatids during mitosis. I. Cell Sci. 105: 41-50.

Carpenter, A.T.C. 1975. Electron microscopy of meiosis in Drosophila melanogaster females. I. Structure, arrangement, and temporal change of the synaptonemal complex in wild type. Chromosoma 51: 157-182.

Castrillon, D.H., P. Gönczy, S. Alexander, R. Rawson, C.G. Eberhart, S. Viswanathan, S. DiNardo, and S.A. Wasserman. 1993. Toward a molecular genetic analysis of spermatogenesis in Drosophila melanogaster: Characterization of malesterile mutants generated by single $P$ element mutagenesis. Genetics 135: 489-505.

Cenci, G., S. Bonaccorsi, C. Pisano, F. Verní, and M. Gatti. 1994. Chromatin and microtubule organization during premeiotic, meiotic and early postmeiotic stages of Drosophila melanogaster spermatogenesis. I. Cell Sci. 107: 3521-3534.

Chen, P., P. Johnson, T. Sommer, S. Jentsch, and M. Hochstrasser. 1993. Multiple ubiquitin-conjugating enzymes participate in the in vivo degradation of the yeast MAT $\alpha 2$ repressor. Cell 74: 357-369.

Cooper, K.W. 1965. Normal spermatogenesis in Drosophila. In Biology of Drosophila (ed. M. Demerec), pp. 1-61. Hafner Publishing, New York, NY.

Counter, C.M., A.A. Avilion, C.E. LeFeuvre, N.G. Stewart, C.W. Greider, C.B. Harley, and S. Bacchetti. 1992. Telomere shortening associated with chromosome instability is arrested in immortal cells which express telomerase activity. EMBO I. 11: 1921-1929.

de Lange, T. 1995. Telomere dynamics and genome instability in human cancer. In Telomeres (ed. E.H. Blackburn and C.W. Greider|, pp. 265-293. Cold Spring Harbor Laboratory Press, Cold Spring Harbor, NY.

Dernburg, A.F., J.W. Sedat, W.Z. Cande, and H.W. Bass. 1995. Cytology of telomeres. In Telomeres (ed. E.H. Blackburn and C.W. Greider), pp. 295-338. Cold Spring Harbor Laboratory Press, Cold Spring Harbor, NY.

Dernburg, A.F., K.W. Broman, J.C. Fung, W.F. Marshall, J. Philips, D.A. Agard, and J.W. Sedat. 1996. Perturbation of nuclear architecture by long-distance chromosome interactions. Cell 85: 745-759.

Deshaies, R.J. 1995. Make it or break it: The role of ubiquitindependent proteolysis in cellular regulation. Trends Cell Biol. 5: 428-434.

Digby, L. 1919. On the archesporial and meiotic mitoses of Osmunda. Ann. Bot. 33: 135-172.

Dutrillaux, B., M.F. Croquett, E. Viegas-Pequignot, A. Aurias, J. Coget, J. Couturier, and J. Lejeune. 1978. Human somatic chromosome chains and rings. Cytogenet. Cell Genet. 20: $70-77$.

Eberhart, C.G. and S.A. Wasserman. 1995. The pelota locus encodes a protein required for meiotic cell division: An analysis of G2/M arrest in Drosophila spermatogenesis. Development 121: 3477-3486.

Fang, G. and T.R. Cech. 1993. The $\beta$ subunit of Oxytricha telo- mere-binding protein promotes G-quartets by telomeric DNA. Cell 74: 875-885.

Foe, V.E. and B.M. Alberts. 1985. Reversible chromosome condensation induced in Drosophila embryos by anoxia: Visualiziation of interphase nuclear organization. J. Cell Biol. 100: 1623-1636.

Gatti, M. and B.S. Baker. 1989. Genes controlling essential cellcycle functions in Drosophila melanogaster. Genes \& Dev. 3: 438-453.

Gatti, M. and M.L. Goldberg. 1991. Mutations affecting cell division in Drosophila. Methods Cell Biol. 35: 543-586.

Gatti, M., S. Bonaccorsi, and S. Pimpinelli. 1994. Looking at Drosophila mitotic chromosomes. Methods Cell Biol. 44: 371-391.

Gilson, E., T. Laroche, and S.M. Gasser. 1993. Telomeres and the functional architecture of the nucleus. Trends Cell Biol. 3: $128-134$.

Giraldo, R. and D. Rhodes. 1994. The yeast telomere-binding protein RAP1 binds to and promotes the formation of DNA quadruplexes in telomeric DNA. EMBO I. 13: 2411-2420.

Girdham, C.H. and D.M. Glover. 1991. Chromosome tangling and breakage at anaphase result from mutations in lodestar, a Drosophila gene encoding a putative nucleoside triphosphate binding protein. Genes \& Dev. 5: 1786-1799.

Girod, P.A., T.B. Carpenter, S. van Nocker, M.L. Sullivan, and R.D. Vierstra. 1993. Homologs of the essential ubiquitin conjugating enzymes $\mathrm{UBCl}, 4$, and 5 in yeast are encoded by a multigene family in Arabidopsis thaliana. Plant J. 3: 545552.

Harley, C.B. and B. Villeponteau. 1995. Telomeres and telomerase in aging and cancer. Curr. Opin. Genet. Dev. 5: 249255.

Hastie, N.D. and R.C. Allshire. 1989. Human telomeres: Fusions and interstitial sites. Trends Genet. 5: 326-331.

Hayashi, K. and W. Schmid. 1975. Tandem duplication q14 and dicentric formation by end-to-end chromosome fusions in ataxia telangiectasia (AT). Humangenetik 30: 135-141.

Henderson, E. 1995. Telomere DNA structure. In Telomeres (ed. E.H. Blackburn and C.W. Greider), pp. 11-34. Cold Spring Harbor Laboratory Press, Cold Spring Harbor, NY.

Hershko, A. and A. Ciechanover. 1992. The ubiquitin system for protein degradation. Annu. Rev. Biochem. 61: 761-807.

Hiraoka, Y., D.A. Agard, and J.W. Sedat. 1990. Temporal and spatial coordination of chromosome movement, spindle formation, and nuclear envelope breakdown during prometaphase in Drosophila melanogaster embryos. I. Cell Biol. 111: 2815-2828.

Hochstrasser, M. 1995. Ubiquitin, proteasomes, and the regulation of intracellular protein degradation. Curr. Opin. Cell Biol. 7: 215-223.

Hochstrasser, M. and J.W. Sedat 1987. Three-dimensional organization of Drosophila melanogaster interphase nuclei. I. Tissue-specific aspects of polytene nuclear architecture. $J$. Cell Biol. 104: 1455-1470.

Hughes-Schrader, S. 1957. Differential polyteny and polyploidy in diaspene coccids (Homoptera: Coccoidea). Chromosoma 8: $709-718$.

Jensen, J.P., P.W. Bates, M. Yang, R.D. Vierstra, and A.M. Weissman. 1995. Identification of a family of closely related human ubiquitin conjugating enzymes. I. Biol. Chem. 51: 30408-30414.

Jentsch, S. 1992. The ubiquitin-conjugation system. Annu. Rev. Genet. 26: 179-207.

Klein, F., T. Laroche, M.E. Cardenas, J.F.-X. Hofmann, D. Schweizer, and S.M. Gasser. 1992. Localization of RAP1 and topoisomerase II in nuclei and meiotic chromosomes of 
yeast. J. Cell Biol. 117: 935-948.

Lindsley, D.L. and G.G. Zimm. 1992. The genome of Drosophila melanogaster. Academic Press, San Diego, CA.

Lipps, H.J., W. Gruissem, and D.M. Prescot. 1982. Higher order DNA structure in macronuclear chromatin of the hypotrichous ciliate Oxytricha nova. Proc. Natl. Acad. Sci. 79: 2495-2499.

Lohe, A.R., A.J. Hilliker, and P.A. Roberts. 1993. Mapping simple repeated DNA sequences in heterochromatin in Drosophila melanogaster. Genetics 13:1149-1174.

Mason, J.M. and H. Biessman. 1995. The unusual telomeres of Drosophila. Trends Genet. 11: 58-62.

Mathog, D., M. Hochstrasser, Y. Gruenbaum, H. Saumweber, and J. Sedat. 1984. Characteristic folding pattern of polytene chromosomes in Drosophila salivary gland nuclei. Nature 308: 414-421.

Mlodzik, M. and Y. Hiromi. 1992. The enhancer trap method in Drosophila: Its application to neurobiology. Methods Neurosci. 9: $397-414$.

Moazed, D. and A. D. Johnson. 1996. A deubiquitinating enzyme interacts with SIR4 and regulates silencing in $S$. cerevisiae. Cell 86: 667-677.

Pardue, M.-L. 1995. Drosophila telomeres: Another way to end it all. In Telomeres (ed. E.H. Blackburn and C.W. Greider), pp. 339-370. Cold Spring Harbor Laboratory Press, Cold Spring Harbor, NY.

Rabl, C. 1885. Über Zelltheilung. Morpholog. Jahrbuch 10: 214330.

Rolfe, M., P. Beer-Romero, S. Glass, J. Eckstein, I. Berdo, A. Theodoras, M. Pagano, and G. Draetta. 1995. Reconstitution of p53-ubiquitinylation reactions from purified components: The role of human ubiquitin-conjugating enzyme UBC4 and E6-associated protein (E6AP). Proc. Nat. Acad. Sci. 92: 3264-3268.

Rubin, G.M. 1978. Isolation of a telomeric DNA sequence from Drosophila melanogaster. Cold Spring Harbor Symp. Quant. Biol. 42: 1041-1046.

Saltman, D., R. Morgan, M.L. Cleary, and T. de Lange. 1993. Telomeric structure in cells with chromosome end associations. Chromosoma 102: 121-128.

Savage, J.R.K. 1970. Sites of radiation induced chromosome exchange. Curr. Top. Radiat. Res. 6: 129-194.

Seufert, W. and S. Jentsch. 1990. Ubiquitin-conjugating enzymes $U B C 4$ and $U B C 5$ mediate selective degradation of short-lived and abnormal proteins. EMBO I. 9: 543-550.

Sheffner, M., J.M. Huibregtse, and P.M. Howley. 1994. Identification of a human ubiquitin-conjugating enzyme that mediates the E6-AP-dependent ubiquitination of p53. Proc. Natl. Acad. Sci. 91: 8797-8801.

Shore, D. 1995 . Telomere position effects and transcriptional silencing in the yeast Saccharomyces cerevisiae. In Telomeres (ed. E.H. Blackburn and C.W. Greider), pp. 139-191. Cold Spring Harbor Laboratory Press, Cold Spring Harbor, NY.

Stack, S.M. and C.R. Clarke. 1973. Differential Giemsa staining of the telomeres of Allium cepa chromosomes: Observations related to chromosome pairing. Can. J. Genet. Cytol. 15: 619-624.

Taylor, A.M.R., J.M. Oxford, and J.A. Metcalfe. 1981. Spontaneous cytogenetic abnormalities in lymphocytes from thirteen patients with ataxia telagenctasia. Int. J. Cancer. 27:311319.

Treier, M., W. Seufert, and S. Jentsch. 1992. Drosophila UbcD1 encodes a highly conserved ubiquitin-conjugating enzyme involved in selective protein degradation. EMBO I. 11: 367-372.

Wagenaar, E.B. 1969. End-to-end chromosome attachments in mitotic interphase and their possible significance to meiotic chromosome pairing. Chromosoma 26: 410-426.

Williams, B.C., M.F. Riedy, E.V. Williams, M. Gatti, and M.L. Goldberg. 1995. The Drosophila kinesin-like protein KLP3A is a midbody component required for central spindle assembly and initiation of cytokinesis. J. Cell Biol. 129: 709-723.

Williams, B.C., M. Gatti, and M.L. Goldberg. 1996. Bipolar spindle attachments affect redistributions of ZW10, a Drosophila centromere/kinetochore component required for accurate chromosome segregation. I. Cell Biol. 134: $1127-1140$

Wing, S.S. and P. Jain. 1995. Molecular cloning, expression and characterization of a ubiquitin conjugation enzyme (E2 $17 \mathrm{~kb})$ highly expressed in rat testis. Biochem. J. 305: 125-132.

Zakian, V.A. 1996. Telomere functions: Lessons from yeast. Trends Cell Biol. 6: 29-33.

Zhen, M., R. Heinlein, D. Jones, S. Jentsch, and E.P.M. Candido. 1993. The $u b c-2$ gene of Caenorhabditis elegans encodes a ubiquitin-conjugating enzyme involved in selective protein degradation. Mol. Cell. Biol. 13: 1371-1377. 


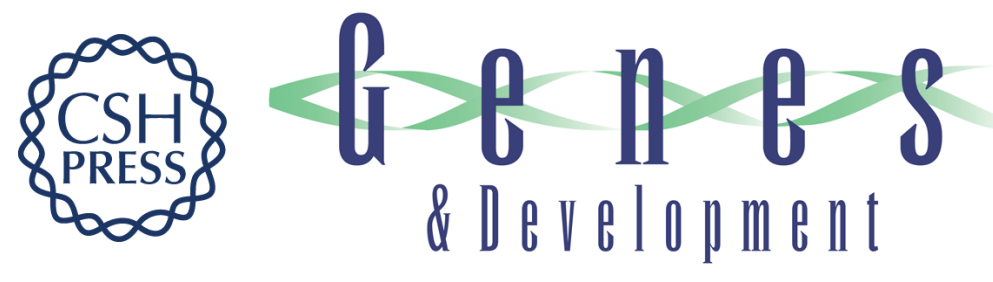

\section{UbcD1, a Drosophila ubiquitin-conjugating enzyme required for proper telomere behavior.}

G Cenci, R B Rawson, G Belloni, et al.

Genes Dev. 1997, 11:

Access the most recent version at doi:10.1101/gad.11.7.863

References This article cites 59 articles, 20 of which can be accessed free at: http://genesdev.cshlp.org/content/11/7/863.full.html\#ref-list-1

License

Email Alerting Receive free email alerts when new articles cite this article - sign up in the box at the top Service right corner of the article or click here.

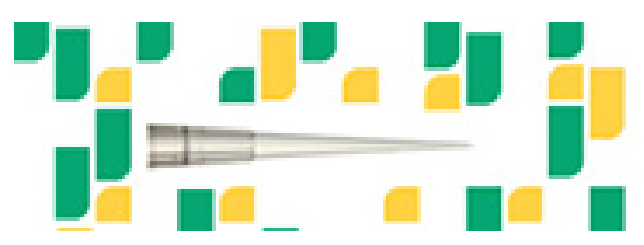

Focused on your science. 